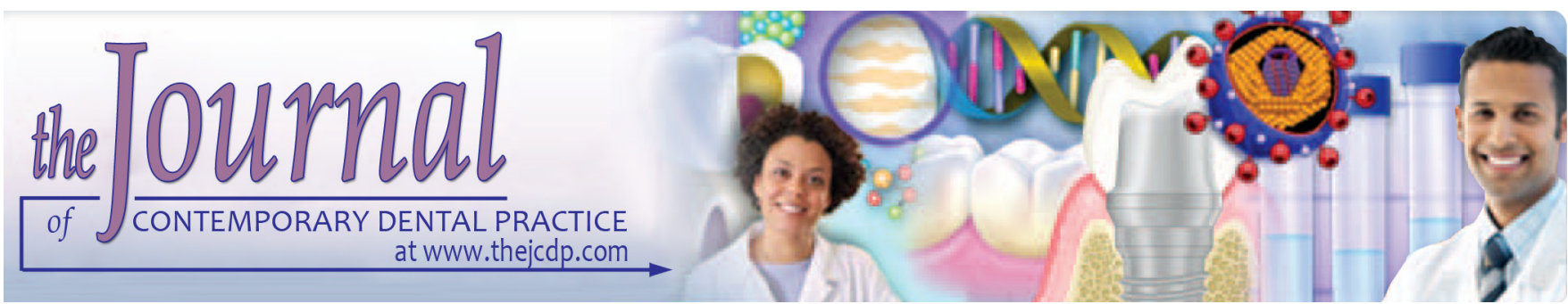

\title{
Delayed Eruption of Maxillary Central Incisors Associated with the Presence of Supernumerary Teeth: A Case Report with 18 Months Follow-up
}

\author{
${ }^{1}$ Abdullah Alsani, ${ }^{2}$ Abdulrahman A Balhaddad
}

\begin{abstract}
Aim: The aim of this study is to discuss a case of an 11-year-old pediatric patient, who was diagnosed with delayed eruption of the permanent maxillary central incisors because of palatally impacted supernumerary teeth.
\end{abstract}

Background: The delayed eruption of permanent teeth can be a result of blocking by supernumerary teeth and over-retained primary teeth. Early diagnosis can help in avoiding the complications. The management of such cases depends on the stage of teeth development, teeth position, and space availability. Treatment may combine both surgical and orthodontic interventions.

Case description: The case was managed by surgically removing the primary retained teeth and supernumerary teeth in two visits then allowing the impacted permanent incisors to erupt without any intervention.

Conclusion: After 18 months follow-up, the two permanent incisors erupted spontaneously with no orthodontic intervention. Clinical significance: dentists should be aware of the importance of early diagnosis of supernumerary teeth. The management of such cases should be designed by a multidisciplinary team decision.

Keywords: Delayed eruption, Diagnosis, Supernumerary teeth.

How to cite this article: Alsani A, Balhaddad AA. Delayed Eruption of Maxillary Central Incisors Associated with the Presence of Supernumerary Teeth: A Case Report with 18 months Follow-up. J Contemp Dent Pract 2018;19(12):1434-1436.

${ }^{1}$ Department of Dental, Armed Forced Hospital at King Abdulaziz Naval Base, Jubail, Saudi Arabia

${ }^{2}$ Department of Restorative Dental Sciences, Imam Abdulrahman Bin Faisal University, Dammam, Saudi Arabia

Program in Biomedical Sciences, University of Maryland School of Dentistry, Baltimore, USA

Corresponding Author: Abdulrahman A. Balhaddad, Department of Restorative Dental Sciences, Imam Abdulrahman Bin Faisal University, Dammam, Saudi Arabia, Phone: +1-317-737-4315 e-mail: aabalhaddad@hotmail.com
Source of support: Nil

Conflict of interest: None

\section{BACKGROUND}

Delayed tooth eruption occurs when the permanent tooth is not found at the expected time to be observed in the oral cavity. ${ }^{1}$ The presence of supernumerary teeth has been identified as the most common reason of delayed eruption of the permanent upper incisors. ${ }^{2}$ Supernumerary teeth can be defined as a hyperactivity of the dental lamina that increases the number of teeth more than the normal count. ${ }^{3}$ It has been found that the prevalence of supernumerary teeth in both primary and permanent dentitions ranges from 0.45 to $2 \%{ }^{4,5}$ Males are twice more likely to have supernumerary teeth than females, and it is seen more frequently in permanent than primary dentition. ${ }^{6,7}$ Complications that are associated with supernumerary teeth are diastema, spacing, teeth malpositioning, root deformation, and follicular cyst formation. ${ }^{8}$

The purpose of this case report is to discuss a case of a pediatric patient with a delayed eruption of the maxillary central incisors because of the presence of two supernumerary teeth and to describe how the case was managed.

\section{CASE DESCRIPTION}

An 11-year-old male patient came to the dental clinics of Imam Abdulrahman Bin Faisal University complaining of a delayed eruption of the upper permanent central incisors. Oral examination revealed that the upper primary central incisors were retained while the other permanent incisors in both arches erupted without any complications. Radiographically, there were two supernumerary teeth apical to the retained primary central incisors, and the 
impacted permanent central incisors were located apical to the supernumerary teeth (Fig. 1). No significant findings were reported in regards to the patient's medical history. In addition, no dental history was reported, as this visit was the first dental visit for this patient. After a consultation with a pedodontist, an orthodontist, and an oral surgeon, it was decided that the optimum treatment for this patient was to remove the retained primary and supernumerary teeth under local anesthesia. Then, the patient and his parents were asked to attend recall visits to observe if the permanent incisors would erupt spontaneously, or else, further action could be needed.

Cone-beam computed tomography (CBCT) radiograph was taken to localize the position of the impacted supernumerary teeth. After taking the father's consent, surgery was planned in two visits. In the first visit, both retained primary teeth were removed. Then, a flap was made palatally from the midline to the right primary canine. After the bone removal, the right supernumerary tooth was lifted using the straight elevator. A resorbable suture was used to stabilize the tissue back (Fig. 2). In the second visit, the left supernumerary tooth was removed in the same manner. It was decided to allow the impacted permanent incisors to erupt without any
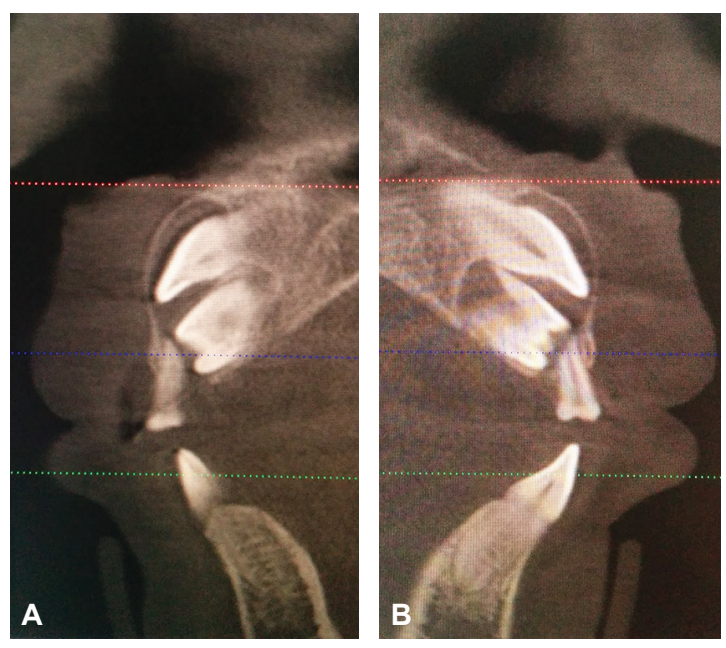

Fig. 1A and B: CBCT showing the position of supernumerary teeth (palatally) in relation to the succeeding teeth. (A) (Right view); (B) (Left view) other action. After 18 months, the two permanent incisors erupted spontaneously without any intervention (Fig. 3). However, it was noticed during the recall visits that the patient had class II molar relationship. He was referred to an orthodontist for further evaluation.

\section{DISCUSSION}

Clinical and radiographic examinations are essential to effectively diagnose supernumerary teeth. The presence of bulge in the mucosa could be an indication for that. Using the CBCT is more accurate to diagnose the presence and location of supernumerary teeth compared to conventional radiographs. The early mixed dentition is the best time to remove supernumerary teeth surgically. ${ }^{9-11}$ The aim of the early intervention is to permit normal eruptive force, which would allow spontaneous eruption of the permanent incisors. Also, the amount of space loss and midline shift could be minimized to prevent the need for an orthodontic intervention in the future. ${ }^{9-11}$ However, it was stated that the surgical removal of supernumerary teeth could be achieved when the incisor root development completed, ${ }^{12}$ or when the roots of the adjacent teeth completed. ${ }^{13}$ Witsenberg and Boering stated in their

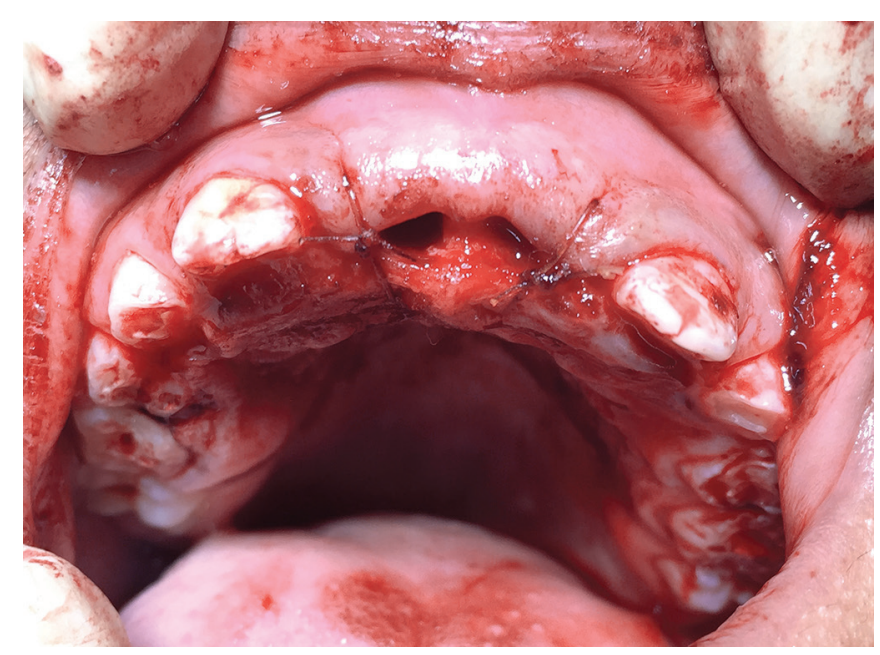

Fig. 2: Clinical photograph after removing the retained upper primary central incisors and the right supernumerary tooth

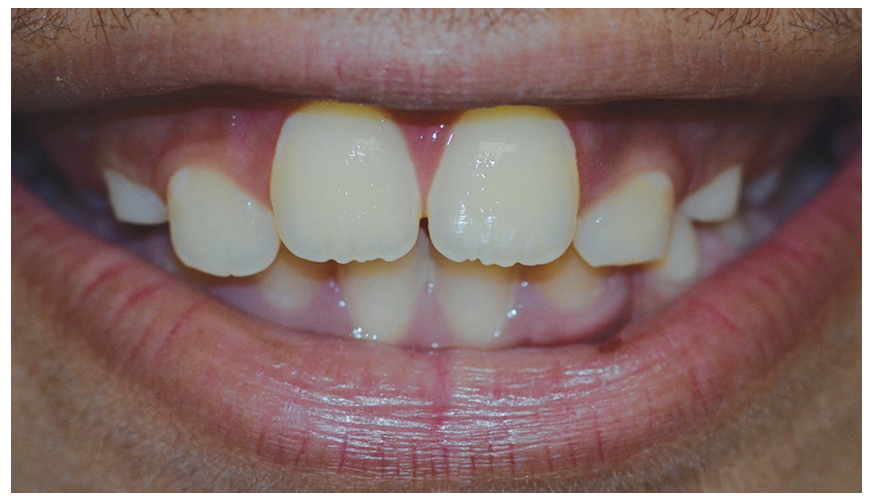

Fig. 3: Eighteen-month intraoral photograph showing the eruption of the upper permanent central incisors 
study that around $54 \%$ of the permanent incisors erupted spontaneously after supernumerary teeth removal. ${ }^{14}$ Another study indicated that the chance of having spontaneous eruption increases with the presence of an adequate space for the eruption, and around $78 \%$ of permanent teeth erupted spontaneously with the median time of 16 months. ${ }^{15}$ Also, it has been found that immature teeth are more likely to erupt spontaneously compared to mature teeth. ${ }^{16}$ Any intervention after the completion of the root apex of unerupted permanent incisors is considered as a late intervention. ${ }^{10}$

In the case of the 11-year-old, it was decided to allow the permanent incisors to erupt without any other intervention, as there was an adequate space. The teeth were kept under continuous evaluation over 18 months to assess any need for an orthodontic intervention.

\section{CONCLUSION AND CLINICAL SIGNIFICANCE}

Early diagnosis of delayed eruption of permanent successors is necessary to avoid many dental complications. The management of such cases should be designed by a multidisciplinary team decision, as there is no definitive time to surgically remove unerupted supernumerary teeth.

\section{ACKNOWLEDGMENTS}

The study was approved by the Scientific Research Unit at the College of Dentistry, Imam Abdulrahman Bin Faisal University as a non-funded research project. Authors have no conflict of interest. We would like to mention our affiliation to Imam Abdulrahman Bin Faisal University as the case report was carried out there.

\section{REFERENCES}

1. Suri L, Gagari E, Vastardis H. Delayed tooth eruption: pathogenesis, diagnosis, and treatment. A literature review. Am J Orthod Dentofacial Orthop 2004 Oct;126(4):432-445.
2. Betts A, Camilleri GE. A review of 47 cases of unerupted maxillary incisors. Int J Paediatr Dent 1999 Dec;9(4):285-292.

3. Díaz A, Orozco J, Fonseca M. Multiple hyperodontia: report of a case with 17 supernumerary teeth with non syndromic association. Med Oral Patol Oral Cir Bucal 2009 May;14(5):E229-231.

4. Luten JR Jr The prevalence of supernumerary teeth in primary and mixed dentitions J Dent Child 1967 Sep;34(5):346-353.

5. Buenviaje TM, Rapp R. Dental anomalies in children: a clinical and radiographic survey. ASDC J Dent Child 1984 Jan-Feb; 51(1):42-46.

6. Moraes RS, Farinhas JA, Gleiser R, Primo LG. Delayed eruption of maxillary permanent central incisors as a consequence of mesiodens: a surgical re-treatment approach. J Clin Pediatr Dent 2004 Spring;28(3):195-198.

7. Bodin I, Julin P, Thomsson M. Hyperodontia. I. Frequency and distribution of supernumerary teeth among 21,609 patients. Dentomaxillofac Radiol 1978;7(1):15-17.

8. Ata-Ali F, Ata-Ali J, Peñarrocha-Oltra D, Peñarrocha-Diago M. Prevalence, etiology, diagnosis, treatment and complications of supernumerary teeth. J Clin Exp Dent 2014 Oct;6(4):e414-418.

9. Solares R. The complications of late diagnosis of anterior supernumerary teeth: Case report. J Dent Child 1990 MayJun;57:209-211.

10. Henry RJ, Post AC. A labially positioned mesiodens: Case report. Pediatr Dent 1989 Mar;11(3):59-63.

11. Högström A, Andersson L. Complications related to surgical removal of anterior supernumerary teeth in children. J Dent Child 1987 Sep-Oct;54(5):341-343.

12. Rajab LD, Hamdan MAM Supernumerary teeth: review of the literature and a survey of 152 cases Int J Paediatr Dent 2002;12:244-254

13. Rao PV, Chidzonga MM. Supernumerary teeth: literature review. Cent Afr J Med 2001 Jan;47(1):22-26.

14. Witsenberg B, Boering G. Eruption of impacted permanent incisors after removal of supernumerary teeth. Int J Oral Surg 1981 Dec;10(6):423-431.

15. Mitchell L, Bennett TG. Supernumerary teeth causing delayed eruption - a retrospective study. Br J Orthod 1992 Feb;19(1):41-46.

16. Mason C, Azam N, Holt RD, Rule DC. A retrospective study of unerupted maxillary incisors associated with supernumerary teeth. Br J Oral Maxillofac Surg 2000 Feb;38(1):62-65. 